taken by the process that wipes the surface clean. The second possible signature of underground processes is a patch of what is termed "chaotic terrain", an almost craterless area made up of short ridges and depressions typically 1 to $3 \mathrm{~km}$ wide and 2 to $20 \mathrm{~km}$ long.

More has been learned about the atmosphere, however. The television experiment detected a multilayer structure at the limb, from about $10 \mathrm{~km}$ up to $50 \mathrm{~km}$, which the infrared spectrometer experiment indicates may be solid carbon dioxide. Dr G. Pimentel reported that there is also infrared evidence for silicate dust in the atmosphere, and a "quite low" abundance of $\mathrm{H}_{2} \mathrm{O}$ may have been detected. New upper limits are being placed on the extent of $\mathrm{NO}, \mathrm{N}_{2} \mathrm{O}$, OCS, $\mathrm{CH}_{4}, \mathrm{O}_{3}$ and $\mathrm{NH}_{3}$. As expected, the ultraviolet spectrometer shows a spectrum similar to the laboratory spectrum of carbon dioxide irradiated by sunlight, but what is odd is the scarcity of atomic oxygen. Carbon dioxide in the laboratory is easily broken down by sunlight. $A$ broad absorption band at $2500 \AA$ interpreted as ozone is detected over the pole caps, but not over the unfrosted areas. Either the pole caps are acting as a cold trap, or for some reason the band is easier to see against a light background. The ultraviolet has also shown that aerosols of sizes less than a tenth of a micron or so are present in large quantities, scattering twice as much light as the atmosphere itself.

It is pleasing that the different methods of drawing the elevation profile of the Martian surface-by radar from the Earth, and by measuring the depth of atmosphere at different points from the intensity of spectral lines-are more or less in agreement in areas where they have all been tried. But the elevation differences that have been measured, possibly as much as $15 \mathrm{~km}$ between highest and lowest points, are comparable with the interval between the deepest ocean and the highest mountains on Earth and raise the question whether isostasy is also at work on Mars.

\section{PALAEOMAGNETISM No Correlations in the Canaries}

\section{from our Geomagnetism Correspondent}

ONE of the most fascinating unsolved problems in palaeomagnetism is the source of the correlations between magnetic polarity and oxidation state found in rocks from certain sites. The construction of a polarity-time scale for the past 4.5 million years, the deduction from magnetic anomalies at sea that alternating periods of normal and reversed polarity extend backwards in time for many tens of millions of years, the evidence from baked contact rocks and the fact that about fifty per cent of the world's rocks are reversely magnetized, leave no doubt that almost all reversed rocks were produced during periods when the Earth's magnetic field was reversed. This being the case, there should be no correlation whatsoever between the magnetic polarity of rocks and their physical, chemical or mineralogical properties. Indeed, the existence of such correlations would be positive evidence for selfreversal, a phenomenon known to exist but support for which is overwhelmed by the evidence in favour of field reversal.

What, then, can be the explanation for the observed correlations? Reversed Quaternary and Tertiary lava flows from Iceland, reversed Tertiary flows from Japan and reversed Carboniferous flows from Scotland all contain significantly more separate ilmenite than the normal flows from those sites; and statistically, the titanomagnetites in reversed Tertiary flows in Scotland, Iceland and the Columbia Plateau, Oregon, and in reversed dykes in Scotland are more highly oxidized than those in the corresponding normal rocks. The first question which needs to be asked is, of course, whether these correlations are fortuitous. After all, they represent a negligible proportion of the world's rocks, and many of these particular samples obey the classic tests for field reversal. The reason why so few correlations have been reported is simply that the work involved is long and tedious. Yet in spite of the small number, they share one property which argues against their arising by coincidence-they are all in the same sense. It is always the reversely magnetized rocks which are, on average, more highly oxidized. never the normal ones.

Even so, the significance of the oxidation-polarity correlations will ultimately be firmly established or rejected by statistics; and that is why a new report by Ade-Hall and Watkins (Geophys. J.. 19, 351; 1970) is important. For these authors have carried out a petrographic and magnetic analysis of 168 Miocene to Pliocene basalt, ankaramate and phonolite lava flows from the Canary Islands, and find no correlation whatsoever between polarity and oxidation. There is. of course, always the possibility that the correlation really exists but is obscured in some way; but Ade-Hall and Watkins have carefully considered this problem and conclude that it does not arise here. It is possible, for example, that a collection which comprises three different rock types, each of which possesses a different but real polarity-oxidation relationship, might exhibit no overall correlation. A separate analysis for each rock type represented, however, revealed a correlation for none. Then again, it is possible that a correlation could be obscured by experimental limitations. It may, have been, for example, that the $\times 1200$ magnification used by Ade-Hall and Watkins in their petrographic analysis was insufficient to resolve fine exsolution of ilmenite in the titanomagnetite grains. This was also ruled out by low temperature Curie point measurements which failed to indicate the presence of any ilmenite at all.

So how does this new non-correlation affect the status of the oxidation-polarity problem in general? The answer is that by itself it makes little difference to the overall situation, for one brick is sufficient neither to build nor to demolish a structure. But it does have a two-fold importance. For one thing, it emphasizes, together with two other non-correlations, that oxidation-polarity relationships are not universal. This in turn serves to emphasize the statistical nature of the whole problem. And second, it stresses that, in this matter, negative results- the absence of correlationare as significant as positive data. The long-term problem is, of course, that a vast amount of work will be necessary on other rock collections before it can be proved that the correlations observed hitherto are not trivial. But if the case is ultimately proved, it will be a major headache for Earth scientists. For, given the reality of field reversal, it is difficult at present to imagine what physical connexion there could be between the oxidation state of lavas which originate in the upper mantle and the magnetic field which is produced in the Earth's core. 